\title{
Mediação artística e saúde coletiva: uma análise psicossocial da experiência de jovens rappers brasileiros e franceses
}

\author{
Artistic mediation and public health: a psychosocial analysis \\ of the experience of young Brazilian and French rappers
}

Ana de Santa Cecilia Massa (https://orcid.org/0000-0001-6250-6806) ${ }^{1}$

${ }^{1}$ Programa Inova Fiocruz, Escola Nacional de Saúde Pública Sergio Arouca, Fundação Oswaldo Cruz. R. Leopoldo Bulhões 1480 , Manguinhos. 21041-210 Rio de Janeiro RJ Brasil. anamassa@hotmail.com

\begin{abstract}
This article discusses the results of research-intervention based on the clinical psychosocial approach conducted among young Brazilian and French rappers between 13 and 27 years of age. Our objective is to analyze the function of rap, as artistic mediation, for the young inhabitants of disadvantaged urban areas. The field research was performed on the basis of participant observation and interviews in both countries. Our analyses show that rap is used by youths to reflect upon the world around them and to react to the negative representations and social imagery with which they are associated, seeking recognition of a positive place in society. Through this artistic expression they become able to accomplish new social and subjective experiences on the social scene. Rap is also a support for the formation of peer groups and social bonds among young inhabitants of different suburbs of the world. In this way, this study seeks to contribute to the discussion surrounding the collective and singular dimension of health practices, thereby constituting a research clinic that does not limit itself to standard technical procedures or to biologically-based scientific knowledge.
\end{abstract}

Key words Youth, Rap, Artistic mediation, Participant observation, Public health
Resumo O presente artigo discute os resultados de uma pesquisa-intervenção fundamentada na abordagem psicossocial clínica realizada junto a jovens rappers brasileiros e franceses, entre 13 e 27 anos. Nosso objetivo é analisar a função do rap, como mediação artística, para os jovens moradores de espaços urbanos desfavorecidos. A pesquisa de campo foi realizada a partir de observação participante e entrevistas nos dois países, entre outubro de 2007 e junho de 2009. Nossas análises mostram que o rap é utilizado pelos jovens para pensar sobre o mundo que os rodeia e para agir sobre as representações e o imaginário social negativos aos quais são associados, buscando o reconhecimento de um lugar positivo na sociedade. Através desta expressão artística podem realizar novas experiências sociais e subjetivas na cena social. O rapé também um suporte para constituição de grupos de pares e para construção de laços sociais entre jovens moradores de diferentes periferias do globo. Buscamos, assim, contribuir para discussão em torno da dimensão coletiva e singular de práticas de saúde, constitutivas de uma clínica que não se limita à procedimentos técnicos padronizados ou aos conhecimentos científicos de base biológica.

Palavras-chave Juventude, Rap, Mediação artística, Observação participante, Saúde coletiva 


\section{Introdução}

O presente artigo busca discutir os resultados de uma pesquisa-intervenção fundamentada na abordagem psicossocial clínica realizada junto a jovens rappers brasileiros e franceses, entre $13 \mathrm{e}$ 27 anos, moradores da Rocinha e Nova Iguaçu, respectivamente uma favela e uma periferia da cidade do Rio de Janeiro e de Blanc-Mesnil, periferia francesa. O rap, ritmo e poesia, juntamente com o DJ - disc jockey - compõem a expressão musical do hip-hop, movimento cultural criado pela juventude negra e latino-americana no Bronx, no final dos anos 1970. O rap é discutido como uma mediação artística que permite ao jovem apreender o mundo que o rodeia, mas também pensar e agir sobre ele. O rap é uma expressão simbólica, situada entre a cena social e a cena psíquica ${ }^{1}$, através da qual o sujeito realiza uma construção de si. Examinaremos a realização do rap Iguaçu-Mesnil, idealizado e composto pelos jovens brasileiros e franceses durante nossa pesquisa de campo, que revela como este trabalho foi utilizado pelos próprios jovens como um meio de criar laços sociais entre eles. Tais vínculos também se concretizaram através do encontro presencial em Blanc-Mesnil, quando brasileiros e franceses puderam realizar oficinas de escrita e gravação de rap, um meio de compartilhar suas experiências nos espaços urbanos onde vivem, o que caracteriza esta pesquisa também como uma intervenção no campo em que foi realizada.

Nosso encontro com jovens rappers nos mostrou que nas particularidades das tramas das sociedades brasileira e francesa uma reivindicação é compartilhada, remetendo a um mesmo sentimento de discriminação e abandono. Os jovens se opõem à negatividade assimilada ao espaço urbano onde vivem, à cor de suas peles ou a suas origens étnicas e culturais. Esta expressão artística se mostrou um meio de compreender o que estes jovens pensam, sentem e agem na realidade social, na encruzilhada entre o que é socialmente estabelecido e subjetivamente vivido. O rap é não apenas um analisador destas juventudes, mas também um suporte para a construção da existência destes jovens, favorecendo novas experimentações sociais e subjetivas na realidade, em busca do reconhecimento de um lugar social positivo na sociedade.

A discussão sobre a expressão de jovens moradores de favelas e periferias através do rap tem relevância em um contexto de insuficiência de políticas de saúde voltadas para a proteção de crianças e adolescentes frente à gravidade das desiguais condições de vida de jovens e de suas famílias nas diferentes regiões do país ${ }^{2}$. Moura et al. ${ }^{3}$ mostram que contextos sociais desfavoráveis estão associados ao aumento dos riscos à saúde e ocorrências de violências nas dinâmicas territoriais das populações (p. 3396). As autoras relatam um processo de "descidadanização" destes jovens, em seus aspectos sociais e subjetivos, provocados pelo fracasso de sistemas de proteção destas juventudes e da perpetuação das injustiças sociais.

Esses jovens são frequentemente mencionados pelos pesquisadores, especialistas em políticas públicas e intervenientes no campo educativo ou sociocultural. Através do rap, posicionam-se como protagonistas, através de uma expressão que afirma a criatividade e autonomia, aqui entendida como a capacidade de compreensão e ação sobre si mesmo e sobre o contexto no qual estamos inseridos ${ }^{4}$. Assis et al. ${ }^{5}$ defendem, neste sentido, o papel de ações de prevenção e de promoção da saúde a partir de uma concepção positiva, que estimulem o potencial criativo e resolutivo dos adolescentes. Para as autoras, uma das missões do sistema de saúde é incluir os jovens como protagonistas do desenvolvimento do autocuidado e de projetos de vida de forma a não ocuparem o lugar de "bode expiatório" dos problemas sociais, passando a participar efetivamente da cena social, como um meio de combater os desafios que enfrentam nesta fase de desenvolvimento. Através do rap, os jovens falam sobre as dificuldades das trajetórias de vida no cotidiano do espaço social onde vivem, o preconceito, o racismo que os fazem ocupar um lugar negativo na sociedade. As narrativas pessoais colocam em evidência a experiência socialmente compartilhada por toda uma juventude que residem em espaços urbanos estigmatizados, em que emerge o "nós", expressão do sujeito social'.

\section{Saúde coletiva, mediação artística e análise psicossocial}

No final dos anos 70 e 80 do século XX, a Saúde Coletiva, até então fundamentado essencialmente pelo referencial teórico estrutural-marxista, passa a incorporar em seu escopo estudos interpretativos, etnográficos e de representações sociais. Tais contribuições ampliaram este campo de estudo, fazendo com que nos anos 90 o tema do sujeito, e também das subjetividades, fossem tratados pela Saúde Coletiva ${ }^{7}$. Colocava-se em discussão o papel do sujeito histórico, em sua dimensão individual e social, na manutenção e na transformação das estruturas nas quais está 
inserido. Isto implicou, necessariamente, uma abordagem interdisciplinar, de forma a buscar em outros campos de conhecimento suportes teóricos e metodológicos que sustentassem as análises dos múltiplos aspectos que revelam a complexidade deste objeto. Ferreira Neto et al. ${ }^{4}$ esclarecem que a noção de subjetividade, quando tratada no campo da Saúde Coletiva, estabelece pontes entre experiências coletivas e individuais, entre dimensões materiais e subjetivas nas práticas de saúde. Não se trata, portanto, de um aspecto intrapsíquico relativo ao sujeito individual, mas de uma construção que se dá na relação com o outro, através da reciprocidade, do encontro com a alteridade na cena social, definição compartilhada pela abordagem psicossocial clínica, que fundamenta a nossa pesquisa.

Sá ${ }^{8}$ afirma que a defesa da abordagem psicossociológica clínica em Saúde Coletiva não se realiza unicamente no plano metodológico. Dá-se também no plano teórico, por reafirmar o projeto interdisciplinar à origem deste campo, e no plano ético-político, por defender a solidariedade e respeito à diversidade. Esta abordagem se caracteriza por apreender seu objeto de pesquisa em suas diferentes dimensões, individual, coletiva, sócio-histórica, afetiva, emocional, por reconhecer o poder metafórico da linguagem e os efeitos das dimensões imaginária e simbólica na vida da sociedade. O sujeito, o sofrimento e a produção de sentido são colocados no centro da análise, o que consolida, segundo a autora, a contribuição desta disciplina para a Saúde Coletiva. Na mesma direção, Paim ${ }^{9}$ indica a necessidade de articular novos paradigmas científicos de maneira a respeitar a historicidade e a integralidade que envolve o objeto complexo saúde-doença-cuidado, que se constrói nos limites do biológico e do social, afirmando o compromisso ideológico da Saúde Coletiva com a transformação social. Para o autor, conciliar este "mundo subjetivo" com o "mundo social" através de uma ação politica emancipatória pode ser um dos maiores desafios para a práxis da saúde coletiva nos tempos atuais. A participação organizada dos grupos sociais, bem como o reconhecimento e o estímulo às iniciativas comunitárias, radicadas na solidariedade, constituem possibilidades de redefinição de relações sociais que poderão auxiliar na redução do sofrimento humano, na elevação da consciência sanitária e ecológica, na preservação da saúde e na defesa da vida (p.16).

O movimento hip-hop é a expressão de jovens moradores de espaços urbanos estigmatizados de diferentes países do globo que lutam por uma sociedade mais justa e igualitária. Ele é uma outra face da globalização, para além de suas dimensões econômica e política. $\mathrm{O}$ rap revela uma globalização sociocultural que permite ao mesmo tempo enraizar em uma particularidade local e o movimento em direção a outras localidades. Encontra-se na encruzilhada entre local e global, formando uma rede de princípios, valores e solidariedade entre grupos de manos, brothers, frères. Jovens no Brasil, nos Estados Unidos e na França referem-se aos pares como irmãos, o que marca a fraternidade dos laços construídos.

A importância do grupo de pares neste momento da vida é discutida por Marcotte et al. ${ }^{10}$, cuja pesquisa preconiza o desenvolvimento de dispositivo com a finalidade de promover o apoio social entres jovens. As autoras enfatizam a importância do vínculo afetivo entre pares como suporte para que possam confrontar os percalços da adolescência, e demonstram o aumento da vulnerabilidade do jovem quando este laço afetivo se rompe ou se ausenta. A imagem corporal negativa, associada à puberdade precoce, é indicada como um fator desencadeador de sintomas depressivos. Os resultados de nossa pesquisa colocam em evidência a mediação artística como um meio em que jovens rappers combatem a imagem negativa que lhes é associada através da discriminação, do racismo, do preconceito que se materializam através da cor de suas peles, da textura de seus cabelos, suas origens étnicas e culturais, de suas maneiras próprias de falar, dos lugares onde moram. É durante a infância e a pré-adolescência que as crianças começam a se comparar, tornando-se particularmente sensíveis ao olhar do outro. A pobreza, o fracasso escolar, as desestruturações familiares, a desqualificação social dos pais e da família os conduzem a interiorizar uma imagem negativa de si próprios. Segundo Vincent de Gaulejac ${ }^{11}$, a humilhação e a vergonha são sofrimentos sociais e psíquicos que nascem na centralidade do olhar do outro. Fazse necessário criar espaços de expressão para que esse sofrimento possa ser exteriorizado, o que possibilitará ao indivíduo sair do isolamento e da culpa individual. Neste sentido, a expressão pelo rap é um antídoto contra a vergonha, um caminho para a resiliência pessoal e social ${ }^{13}$. A mediação simbólica através do rap traz a possibilidade de criar novos sentidos para a existência, de resistir à ideia de se sentir reduzido a um estigma, ao mesmo tempo que reafirma o laço social, por se realizar através de produção individual e coletiva endereçada ao outro, à sociedade.

A expressão através do rap não se restringe aos jovens moradores de territórios urbanos es- 
tigmatizados. No entanto, ela é investida de um sentido particular para estas juventudes, na medida em que é utilizada como um meio de expressão individual e coletiva. Os temas tratam da relação com o espaço social onde vivem, mas também da relação com a sociedade como um todo. Moura et al. ${ }^{3}$ investigaram a injustiça social e as limitações das capacidades humanas que caracterizam a violação de direitos fundamentais que podem reduzir as oportunidades dos jovens de experimentar e concretizar a autonomia e as utopias de seus projetos de vida (p. 3396). As autoras apontam que a situação destes jovens é determinada não somente pelo aspecto econômico associado à lógica neoliberal, mas também pelas desigualdades nas relações de poder material, cultural e simbólico, assim como pela impossibilidade de transformar suas qualidades de vida. $\mathrm{Na}$ mesma direção, Onocko-Campos ${ }^{7}$ propõe o desenvolvimento de estudos sobre o sofrimento psíquico que emerge nas periferias das grandes cidades na contemporaneidade. Frente às subjetividades fragilizadas, violentadas pelas desigualdades sociais, pela pobreza, pelas discriminações e preconceitos, a autora aponta para a necessidade de diferenciar estratégias em múltiplos planos: sanitário, clínico, social e produtivo.

Investigamos o rap como meio dos jovens expressar a violência vivida, mas também de denunciar e combater as representações hegemônicas ligadas às periferias e favelas, produzindo uma tensão entre discursos de dominantes e dominados. A mediação simbólica impede que suas subjetividades sejam invadidas pelo estigma, pela violência simbólica produzida pela associação destes jovens a um imaginário perigoso, que os assimila à criminalidade e à violência. Através da criação de palavras, rimas e sons, jovens produzem novas representações do espaço e de si, posicionando-se como sujeito da linguagem, produtores de sentidos e significados. A (re)significação de imagens e símbolos que lhes são associados participam de uma luta subjetiva e social contra o assujeitamento e dominação social. Os jovens são confrontados à tarefa de construir sentido a partir de uma existência precária, cujo impasse está na origem do seu sofrimento. Cada um afeta o grupo pela sua experiência pessoal e é afetado pela experiência do outro, em um movimento de ressonâncias mais amplo, que dá força à construções de novas subjetividades e de laços entre favelas e periferias de diferentes continentes.

\section{Método}

Para Minayo ${ }^{12}$, a relevância das contribuições das metodologias qualitativas está na possibilidade de examinar lógicas internas de grupos e atores, assim como valores culturais e representações associados as suas histórias, investigando os "níveis mais profundos das relações sociais”. A autora ressalta a importância de levar-se em conta a construção de significado, a intencionalidade dos atos e suas relações com as estruturas sociais, entendidas como construções humanas, durante a realização de uma pesquisa. Turato ${ }^{13}$, na mesma direção, salienta a exigência da escuta e da observação dos sujeitos, marcando a especificidade do método clínico-qualitativo no que tange à produção de sentido e de significação durante este tipo de pesquisa, tomada como um processo.

A abordagem psicossocial clínica, mais especificamente, tem sido utilizada no ensino e em diferentes pesquisas-intervenções no campo da saúde direcionadas à relação de cuidado e de práticas em saúde ${ }^{8}$. Recursos como a construção de narrativas de situações profissionais são utilizados para fazer emergir o discurso do sujeito que, através da mediação simbólica da linguagem, busca produzir sentido para a produção de cuidado realizada em uma situação social. Em nossa pesquisa, realizamos uma observação participante orientada pela psicossociologia clínica como um meio de apreender as experiências dos jovens no universo do rap, nos posicionando, como indica Vincent de Gaulejac ${ }^{14}$, o mais perto do vivido pelo sujeito, o que caracteriza a postura clínica. A observação participante é definida por Lapassade $^{15}$ como um período de interações sociais intensas entre o pesquisador e os sujeitos, no meio destes últimos. (...) Ao longo do trabalho de campo, o observador participante, tomando parte da vida coletiva daqueles que ele observa, ocupa-se essencialmente de olhar, escutar, conversar com as pessoas, coletar e reunir informações. Ele se deixa levar pela situação (p. 375). Em nossa pesquisa, a observação participante foi associada à postura clínica da pesquisadora.

Na perspectiva teórico-metodológica psicossociológica, a postura clínica coloca em evidência a singularidade da relação estabelecida entre pesquisador e pesquisado, entre dois sujeitos na situação de pesquisa ou intervenção. Barus-Michel ${ }^{16}$ indica a assimetria da relação de poder entre médico, investido de um saber sobre a doença, e o paciente que a vive, que sente e experiencia aquilo que o acomete. Portanto, o médico deve se colocar em posição de escuta do paciente, condi- 
ção para compreender aquilo que este sabe sobre si. A abordagem psicossocial clínica exige que o pesquisador seja capaz de criar laços, estabelecer uma relação com o sujeito que participa de sua pesquisa, como condição para a coconstrução de um conhecimento, que emerge da relação intersubjetiva entre pesquisador e pesquisado. No entanto, para Florence Giust-Desprairies ${ }^{17}$, a coconstrução de um conhecimento não deve ser entendida simplesmente como uma participação dos sujeitos à produção de um material proveniente de uma experiência comum com o pesquisador. $\mathrm{O}$ conhecimento clínico inclui a compreensão, a atividade representativa e simbolizante dos próprios sujeitos que participam da pesquisa. Exatamente por se tratar de uma reapropriação subjetiva, por definição nunca completada, a abordagem clínica não é uma ciência que explica efeitos por causas, mas uma hermenêutica de processos através dos quais são produzidas significações (p.120). A postura clínica é, portanto, a antítese da postura do expert, do especialista, que detém um conhecimento sobre determinada situação.

A psicossociologia clínica não define apenas uma questão metodológica, mas epistemológica, na medida que determina a singularidade da produção de um conhecimento. O que pode ser observado durante uma observação participante é aquilo que pode ser vivido entre pesquisador e pesquisado, que não se revela da mesma maneira a todos os pesquisadores. Neste sentido, a abordagem clínica nos convida a apreender os movimentos transferenciais que atravessam a pesquisa e que colocam as perguntas: quem é o pesquisador para o pesquisado? Quem é o pesquisado para o pesquisador? Trata-se de uma produção subjetiva e inconsciente enraizada em um contexto social. Através da palavra endereçada, pesquisador e pesquisado explicitam suas representações do outro, deles mesmos e do mundo que os rodeia, tornando-se assim um material privilegiado para a construção de um saber sobre um objeto.

A abordagem psicossocial clínica pressupõe um método de análise que permita a articulação entre determinantes heterogêneos, entre o psíquico e o social, o que caracteriza a complexidade clínica. Segundo Morin ${ }^{18}$, o pensamento complexo se opõe ao pensamento positivista, que reduz o objeto investigado, dividindo e isolando aquilo que, por outro lado, se religa e interfere. Há, neste sentido, uma solidariedade entre elementos que não devem ser dissociados, afirmando a multidimensionalidade das realidades. Uma abordagem complexa não deve ser confundida com a pretensão da construção de um saber totalizante, capaz de apreender a totalidade de um objeto. Tal perspectiva vai na direção da produção de um saber não compartimentado, capaz de se confrontar com o real, admitindo que a realidade vai além da capacidade de apreensão e análise do pesquisador. A parcialidade do saber produzido remete à singularidade da produção de cada pesquisa, determinada pelo ponto de vista e pela implicação do pesquisador.

A observação participante clínica foi realizada entre outubro de 2007 e junho de 2009, alternando períodos entre Blanc-Mesnil, periferia da região parisiense, e Rocinha e Nova Iguaçu, no Rio de Janeiro. Realizamos, também, 19 entrevistas individuais e coletivas, sendo nove em Blanc Mesnil (quatro individuais e cinco coletivas) e dez entrevistas no Rio de Janeiro (nove individuais e uma coletiva). Inicialmente, pretendíamos realizar entrevistas como dispositivo metodológico para apreender a função simbólica do rap e como esta mediação artística poderia ser utilizada como suporte pelos jovens. No entanto, durante a pesquisa de campo, os próprios jovens nos mostraram que o caminho para compreender a relação que estabeleciam com o rap era compartilhando lado a lado suas experiências, através das oficinas, dos momentos de gravação e das atividades das associações. Durante a entrevista, não manifestavam interesse em conversar sobre os sentidos de escrever um rap, inclusive vários deles aceitaram participar das entrevistas depois do processo de construção dos laços entre pesquisador e pesquisado. A realização de entrevistas, que testemunhavam o vínculo dos jovens com a pesquisadora, seria uma complementação daquilo que a pesquisadora poderia apreender a partir da experiência compartilhada com os jovens no universo do rap, reunindo diferentes tipos materiais como um bricoleur ${ }^{13}$.

Em Blanc-Mesnil, a observação participante clínica foi realizada entre outubro de 2007 e julho de 2008 e, noutro momento, entre fevereiro de 2009 e junho de 2009. Entre os dois momentos foi realizada a pesquisa de campo no Brasil. Durante este período, acompanhamos e participamos das atividades de uma associação criada por três jovens adultos moradores do Blanc-Mesnil, com o objetivo de reunir os jovens rappers da região para compor e gravar seus raps, promovendo encontros e facilitando a criação de projetos conjuntos. Acompanhamos todas as atividades propostas pela associação: Projeto Unidade em Blanc-Mesnil (seis oficinas entre janeiro e feve- 
reiro de 2008), Projeto Free Style I (seis oficinas durante as férias de inverno de 2008), Projeto Free Style II (seis oficinas durante férias de Páscoa de 2008), Projeto Foto, realização de fotografias da região (uma oficina durante férias de Páscoa de 2008), Projeto Sábados Livres, sala aberta para jovens compor e gravar raps (sete oficinas), Projeto França x Brasil, preparativos do encontro de jovens rappers brasileiros e franceses em BlancMesnil (entre fevereiro 2009 e junho de 2009), realização do Projeto França x Brasil (10 a 20 de junho de 2009).

No Rio de janeiro, a pesquisa de campo foi realizada entre agosto de 2008 e janeiro de 2009. Contou com uma fase exploratória do campo, quando conhecemos diferentes iniciativas locais criadas pelos próprios jovens em torno do rap e da cultura hip-hop, em diferentes favelas e periferias do Rio de Janeiro. Decidimos acompanhar as oficinas de escrita de rap na Rocinha e as atividades de uma associação em Nova Iguaçu, suas oficinas de DJ e de militância (entre setembro e dezembro de 2008), e ainda oficinas de composição do rap Iguaçu-Mesnil (outubro de 2008). Na Rocinha, acompanhamos as oficinas de rap conduzidas por um rapper profissional para os jovens moradores (outubro a dezembro de 2008).

\section{Resultados}

Segundo os dados do Instituto Nacional de Estatística e de Estudos Econômicos (INSEE) de 2008 , no decorrer desta pesquisa $20,8 \%$ da população de Blanc Mesnil era de origem estrangeira, contra 12,4\% da região Ilha de França. A taxa de desemprego da população entre 15 e 64 anos era de $16,2 \%$, bem superior à taxa de $10,8 \%$ da região. Por outro lado, a população acima de 15 anos não escolarizada não tinha qualquer diploma, quase o dobro da taxa de $17,9 \%$ da região. No que tange à cidade de Nova Iguaçu, segundo o Censo de 2010, sua população é predominantemente composta de cor ou raça preta e parda (63\%). Seu Índice de Desenvolvimento Humano Municipal (IDHM) é de 0,713 , colocando-a na $17^{a}$ posição no ranking de cidades deste porte. Em 2018, o salário médio mensal era de 2,1 salários mínimos. A proporção de pessoas ocupadas em relação à população total era de 13,1\% e $38,7 \%$ da população vive em domicílios com rendimentos mensais de até meio salário mínimo por pessoa.

A realização da pesquisa foi uma oportunidade aproveitada pelos jovens moradores de Nova
Iguaçu e de Blanc-Mesnil para compor um rap conjuntamente e colocar em diálogo suas realidades. Sua sonoridade, ritmo e letra dão forma aos vínculos criados entre eles e entre nós. Iguaçu-Mesnil é um nome híbrido, um neologismo que designa um espaço imaginado. Ao colocar em evidência os nomes próprios das periferias, os jovens criam um terceiro espaço que simboliza um lugar de encontro e de criação, ao mesmo tempo que marcam a existência e a singularidade destes espaços sociais. Ancorando-se em suas experiências nos lugares ondem moram, encontram o caminho para descobrir o outro lado do Atlântico. Os jovens brasileiros e franceses desejavam mostrar seus raps, mas também conhecer como o outro fazia rap. A pesquisa tornava-se apropriada e instrumentalizada pelos jovens.

As oficinas de escrita do rap foram precedidas da realização de debates cujo objetivo era pensar as diferenças e as proximidades do vivido pelos jovens de periferias francesas e favelas brasileiras. Tais debates foram realizados em Nova Iguaçu e em Blanc-Mesnil. A criação de um espaço de discussão junto aos jovens sempre foi um desafio em Blanc-Mesnil, mas a associação à criação de um rap com jovens brasileiros fez com que se interessassem e se investissem na discussão. A reflexão sobre diferenças entre periferias e favelas conduziram os jovens franceses a pensar sobre outras diferenças. Para Winnicott ${ }^{1}$, um objeto transicional pode simbolizar a união entre duas coisas em que há uma separação, remetendo à relação entre o bebê e a mãe. O rap, tomado como um objeto transicional, introduz uma mediação simbólica que os apoia para pensar sobre a experiência que se constitui entre a França e o bled (palavra em árabe que utilizam para fazer referência ao país de origem dos pais), entre a sociedade global e as periferias e favelas, entre a França e o Brasil, entre Nova Iguaçu e Blanc-Mesnil, entre si mesmos e o outro. Os jovens utilizam o rap para tecer laços e para pensar as tensões que produzem rupturas e aproximações entre países, espaços sociais, sociedades e os cidadãos.

Todo o processo foi feito pelos jovens, com seus próprios recursos. A mixagem do rap ficou a cargo dos brasileiros, que receberam as estrofes gravadas através da internet. A interposição das gravações fez com que o rap fosse editado como um diálogo, uma estrofe em francês e outra em português, na batida do rap, como segue:

Essa daqui vai direto pra França, Baixada, RJ, nóis[sic] brota no peito a última esperança. / Desde criança mó [sic] confiança pra rimar, representar, subir no palco, ideia pra trocar. / Rá-tá-tá-tá-tá, 
descarregando a mente. / Sou Tiba XI, parceiro, mais um sobrevivente. (Jovem rapper brasileiro A)

\section{(...)}

Meu ódio e minha raiva, é sobre isso que eu falo. / Eu falo para vocês sobre discriminação. / Na França ou no bled eu venho da imigração, o que eu compartilho com o Brasil é minha paixão. / Eu sou de origem marroquina, parece que você acha isso arrogante. / Diga para mim o que te incomoda, éo racismo que eu acho constrangedor. (Jovem rapper francês A)

(...)

Deus tá [sic] com a gente, represento o Rio de Janeiro. / Da cidade maravilhosa pro mundo inteiro. / Eu sou guerreiro porque é assim que tem que ser. / Porque o sistema na Baixada limita você. (Jovem rapper brasileiro B)

(...)

Eu não desisto, persevero na missão. / Busco sabedoria pra não viver na contramão. / Revolução, vou te mostrar como se faz. / Meu nome é Wilson, eu tô lutando pela paz. (Jovem rapper brasileiro C)

(...)

Do Blanc-Mesnil ao Brasil. / Vende-se resina. / Escuta primo, escuta prima. / As crianças andam com fuzil./ São quilos de cocaína que sustentam a usina./ As armas, as drogas, nos fascinam. / A vida aqui é muito mais fácil do que a de lá. / Então por quê reclamamos?/ Tem algo que não está certo. / Da periferia de Paris para as favelas, infelizmente. / Lá, depois dos vinte anos você não vive. (Jovem rapper francês B)

(...)

A noite cai, me atrai, nóis [sic] sai pra ver qualé [sic]. I Rio de Janeiro, os parceiros sobrevivem na fé. / Tô ligado qualé [sic], Nova Iguaçu é quente. / Daqui direto pra França descarregando o pente. (Jovem rapper brasileiro A)

(...)

Minha raiva eu solto no rap francês. / Não são só vocês, irmãos, Nós também ... (Jovem rapper francês C)

Jovens brasileiros e franceses se constituíam, uns para os outros, como destinatários imaginários de suas composições. Eles se apresentavam, perguntavam sobre a realidade do outro e se apoiavam mutuamente. Um dos rappers brasileiros nos disse: eu não preciso compreender a língua dele, nem ele a minha para escrever um rap juntos. Basta que a gente saiba sobre o que a gente quer falar e sai perfeitamente na música.

No seio do campo discursivo criado pelo rap, os jovens simbolizam a aliança imaginária entre as favelas e as periferias, entre manos, bro- thers, frères, integrando-os à família criada pelo hip-hop. Ele cria uma base comum que reúne singularidades das experiências ligadas à discriminação e ao racismo, na França e no Brasil. Osumare $^{22}$ nomeou como "marginalidade conectiva" a capacidade deste movimento cultural reunir e dar expressão a histórias de opressão de populações de diferentes nações. O compartilhamento de afetos e de pensamentos através do rap participa assim da construção do vínculo social, entre jovens, entre grupos de pares. Tais experimentações subjetivas evocam a dialética entre o "eu" e o "nós", à origem do sujeito social. BarusMichel ${ }^{6}$ ressalta, no entanto, que a unidade do sujeito social não é efetiva na realidade. A unidade do enunciado é uma ficção com uma função continente que afirma o pertencimento ao coletivo. Essa união se consolida, de um lado, por um ideal imaginário que coloca a coincidência entre desejos individuais e, de outro lado, pelo compartilhamento simbólico de um discurso que promove uma causa comum. Se a ação une os indivíduos, ela não pode abarcar toda a diversidade de aspirações que nela são investidas. A experiência do hip-hop revela-se assim atravessada pela dialética do individual e do coletivo, do local e do global.

O refrão do rap, feito por um francês, afirma sua força através do uso do verlan (palavras pronunciadas de trás para frente, em francês), das gírias, das palavras utilizadas pelos jovens moradores da periferia francesa. O último verso é incompreensível para um francófono que não conhece os códigos da periferia francesa. Paradoxalmente, estas palavras codificadas se apresentam como um meio para transmitir uma mensagem ao interlocutor brasileiro. Elas se associam à criação de uma sonoridade explosiva, de uma dicção ritmada, dando forma a uma interpretação que exprime a revolta. Gírias e expressões locais, trabalhadas a partir da performance do rapper, permitem o compartilhamento da experiência de discriminação e de racismo entre jovens que não falam a mesma língua, ao mesmo tempo que afirmam singularidades culturais, sociais e linguísticas locais. Mas o refrão em francês faz também referência às "favelas do mundo", que pode ser entendido como a expressão de uma identificação com o sofrimento social e do reconhecimento simbólico do vivido pelo semelhante.

A expressão dos jovens rappers franceses coloca em evidência uma manifestação viva da raiva, e faz um convite à performance que exteriorize a revolta. A interpretação dos brasileiros aposta num swing, tem uma locução suave, arre- 
dondada e envolvente. Para os jovens brasileiros, o discurso é positivado através de uma mensagem de pacificação que vai na direção da esperança e da sabedoria. O rap é apresentado como meio de expressão de ideias. A onomatopéia da descarga da metralhadora é utilizada para exprimir a exteriorização do pensamento, combate claramente situado no campo simbólico, apoiando-se na função de continente da mediação artística. $\mathrm{O}$ compartilhamento dos afetos e dos pensamentos através do rap participam da construção do laço social, na encruzilhada entre o retorno a si mesmo e o encontro com a alteridade. Para Takeuti ${ }^{19}$, tais experiências de subjetivação coletiva através do hip-hop permitem sair de impasses repetitivos, o indivíduo podendo ressingularizar-se através do encontro com outros rappers, permitindo a cada um contribuir com conhecimentos e saberes adquiridos em outros universos.

Após a realização virtual do rap Iguaçu-Mesnil, quatro jovens brasileiros foram ao encontro dos franceses em Blanc-Mesnil. A associação era reconhecida como Ponto de Cultura e, através da aprovação de um projeto de intercâmbio internacional, obtiveram do Ministério da Cultura o custeio das passagens aéreas. As despesas locais foram pagas pela Prefeitura de Blanc-Mesnil. Podiam assim dar continuar às trocas que haviam começado pela internet, ampliar a rede através de experiências associativas internacionais e divulgar o trabalho como rappers. Este projeto, intitulado França x Brasil, permitia os jovens brasileiros dar um passo a mais na conquista social apoiando-se no hip-hop: eles vinham ao encontro da Europa, continente investido por um imaginário que o associa à cultura, ao saber, ao sucesso, inacessível aos habitantes das periferias brasileiras, atravessando assim uma barreira social e simbólica.

As atividades do Projeto França X Brasil reuniram cerca de cinquenta jovens franceses em Blanc-Mesnil durante 15 dias. Foram realizados debates, oficinas de rap e de DJ, criação e gravação de raps entre jovens franceses e brasileiros. O número de jovens testemunhava o interesse no encontro com os brasileiros, mas o encontro físico colocava em evidência as diferenças entre eles. Além da barreira da língua, que era parcialmente ultrapassada pelas traduções feitas pela pesquisadora, a ambivalência entre atração e hesitação revelava que havia uma relação real ainda a ser construída. A comunicação se desenrolou sobretudo através da música, da gravação, da escuta de diferentes maneiras de cantar e fazer rap. Certos códigos do hip-hop, como vestuários (bonés, ca- sacos, calças e blusas largas), mas também a maneira de sustentar e mexer o corpo, de se cumprimentar tornavam visíveis seus pertencimentos a este movimento cultural.

A realização destes dois projetos, primeiramente o rap Iguaçu-Mesnil e em seguida o Projeto França X Brasil, criou passarelas permitindo trocas em dimensões locais e internacionais, o que permitiu o acesso a experimentações de outros universos sociais, mostrando que o rap pode ser uma mediação para o encontro da alteridade, à origem da construção do laço social. Mas, como toda experiência ancorada em uma realidade social complexa, o rap é também atravessado por contradições e ambivalências que revelam a intensidade do investimento nesta expressão artística daqueles que lutam por uma existência social, por um futuro que não seja fadado à precariedade.

\section{Discussão}

O rap, em sua função de mediação simbólica, oferece ao jovem um suporte para produzir sentido para suas experiências, criar novas significações para trajetórias pessoais. Esta expressão artística cria um espaço intermediário entre o mundo interno e o mundo externo do sujeito ${ }^{1}$, no seio do qual realiza a atividade criativa, através da produção de um discurso, sonoridade e performance que agem sobre representações sociais, produzindo um efeito sobre o imaginário social negativo ao qual estão associados. Neste processo, exteriorizam as causas de sua desvalorização social, o que os protege de vivê-la sob o prisma da culpa, da vergonha, em uma sociedade meritocrática, em que cada um é reenviado à responsabilidade de seu sucesso pessoal. O rap é um continente simbólico que dá possibilidade para a expressão do conflito, da raiva, da revolta, função que deve ser resguardada de uma instrumentalização de cunho moralista e normativo que o tomaria com o objetivo de pacificar um suposto potencial violento destes jovens.

Nossa pesquisa mostrou que a expressão através do rap ganha sentido no seio do grupo de pares, como uma manifestação coletiva, que sustenta a ação na direção de um projeto comum. Em um mundo globalizado, o rap se apresenta como uma manifestação que associa periferias e favelas do globo. A expressão de uma experiência em uma localidade ressoa com o vivido por juventudes em periferias de outros grandes centros urbanos, produzindo processos identificatórios que conduzem jovens a se inscreverem em um 
coletivo que reúne diferentes espaços urbanos, cores de pele e etnias, formando uma comunidade imaginária, transnacional, multirracial e multilíngue $^{20}$. $\mathrm{O}$ rap abre, na pós-modernidade, uma via que favorece o deslocamento de jovens, abrindo-se à novas experiências subjetivas e sociais, desenvolvendo potenciais e denunciando injustiças vividas no seio da sociedade.

\section{Conclusão}

A produção de narrativas de jovens a fim de compartilhar o que vivem e exteriorizar as emoções se apresenta como uma fala endereçada ao outro, real e imaginário, com quem entretêm uma relação dialógica, confirmando o pacto social no seio da comunidade. A construção da subjetividade passa pela interiorização de formas de reconhecimento social ${ }^{21}$. O rap se apresenta, antes de mais nada, como expressão da vontade dos jovens de produzirem laços, de ter um lugar social valorizado através do reconhecimento daquilo que eles são. Neste sentido, são unânimes em recusar a ideia segundo a qual o rap seria uma expressão violenta, e defendem que esta mediação artística é um meio de exprimir a violência que eles vivem, com o objetivo de serem compreendidos pelo outro e de compartilhar $\mathrm{o}$ que vivenciam. Ele abre às possibilidades de deslocamentos de experiências e construções identitárias, que revelam a necessidade de sair das identidades cristalizadas, que caracterizam o estigma, para se abrir à multiplicidade e mobilidades de pertencimentos.

Através desta discussão, buscamos contribuir para a reflexão sobre a utilização da mediação artística como uma possibilidade de um trabalho sobre representações e sobre a construção de sentido associada às práticas de saúde e à relação de cuidado. Elas apontam para a dimensão coletiva e singular que estas deveriam assumir, reconhecendo a tensão irredutível entre essas duas dimensões como constitutivas de uma clínica que não pode, sob pena de perder sua eficácia e efetividade, se limitar aos procedimentos técnicos padronizados ou aos conhecimentos científicos de base biológica. 


\section{Referências}

1. Winnicott W. Jeu et réalité. Paris: Éditions Gallimard, Folio Essais; 1975.

2. Costa MCO, Assis SG, Hébert M. Risco e proteção à saúde e bem-estar na infância e adolescência. Cien Saude Colet 2014; 19(3):660-661.

3. Moura LBD, Oliveira C, Vasconcelos AMV. Violências e juventude em um território da Área Metropolitana de Brasília, Brasil: uma abordagem socioespacial. Cien Saude Colet 2015; 20(11):3395-3405.

4. Ferreira Neto JL, Kind L, Pereira AB, Rezende MCC, Fernandes ML. Usos da noção de subjetividade no campo da Saúde Coletiva. Cad Saude Publica 2011; 27(5):831-842.

5. Assis SG, Avanci JQ, Duarte CS. Adolescência e saúde coletiva: entre o risco e o protagonismo juvenil. Cien Saude Colet 2015; 20(11):3296-3297

6. Barus-Michel J. Le sujet social, Etude de psychologie sociale clinique. Paris: Éd. Dunod; 1987.

7. Onocko-Campos R. Psicánalise e saúde coletiva. Interfaces. São Paulo: Hucitec Editora; 2012.

8. Sá MS. Por uma abordagem clínica psicossociologia de pesquisa e intervenção em saúde coletiva. In: Azevedo CS, Sa MS, organizadores. Subjetividade, gestão e cuidado em saúde. Abordagens da psicossociologia. Rio de Janeiro: Editora Fiocruz; 2013. 153-205.

9. Paim JS, Almeida Filho N. Saúde coletiva: uma "nova saúde pública" ou campo aberto a novos paradigmas? Rev Saude Publica 1998; 32(4):299-316.

10. Marcotte D, Lemieux A. A trajetória dos sintomas depressivos da infância para a adolescência e objetivos da intervenção preventiva. Cien Saude Colet 2014; 19(3):785-796

11. Gaulejac V. Les sources de la honte, Paris: Éd. Desclée de Brouwer; 2008.

12. Minayo MCS. O desafio do conhecimento. Pesquisa qualitativa em saúde. $9^{a}$ ed. revista e aprimorada. São Paulo: Hucitec; 2006

13. Turato ER, Tratado da metodologia da pesquisa clínico-qualitativa: construção teórico-metodológica, discussão comparada e aplicação nas áreas da saúde e humanas. 6a Ed. Petrópolis: Editora Vozes; 2013.
14. Gaulejac V, Hannique F, Roche P. La sociologie clinique, enjeux théoriques et méthodologiques. Toulouse: Éd. Érès; 2007.

15. Lapassade G. Observation participante In : Barus Michel J, Enriquez E, Levy A, organizadores. Vocabulaire de psychosociologie, Toulouse: Éd. Érès; 2006.p. 375390.

16. Barus-Michel J. Le chercheur premier objet de la recherche. Bulletin de psychologie 1986; Tome XXXIX, $\mathrm{n}^{\circ}$ 377, 801-804.

17. Giust-Desprairies F. Le désir de penser. Construction d'un savoir clinique. Paris: Éd. Téraèdre; 2004.

18. Morin E. Introduction à la pensée complexe. Paris: Éditions du Seuil; 2005.

19. Takeuti N. Movimentos culturais juvenis nas "periferias" e inventividades sociais" In: Martins $\mathrm{PH}, \mathrm{Me}-$ deiros R, organizadores. América Latina e Brasil em perspectiva. Recife: Editora Universitária UFPE; 2009. p. 331-350.

20. Morgan M, Bennett D. Hip-Hop \& the Global Imprint of a Black Cultural Form. Daedalus 2011; 140(2):176196.

21. Carreteiro TC. Jeunesses brésiliennes, institutions et changement dans les groupes défavorisées. Adolescence 2007; 1(59):61-71.

22. Osumare H. The Africanist Aesthetic in Global HipHop: Power Moves. $8^{\mathrm{a}}$ ed. Londres: Palgrave Macmillan; 2008.

Artigo apresentado em 28/04/2020

Aprovado em 06/04/2021

Versão final apresentada em 08/04/2021

Editores-chefes: Romeu Gomes, Antônio Augusto Moura da Silva 